\title{
A SWOT Analysis of Urology Residency
}

\author{
Luke E. Sebel $^{1}$ - Eric G. Katz ${ }^{1}$ Lara S. MacLachlan ${ }^{10}$
}

Accepted: 17 October 2021 / Published online: 16 December 2021

(C) The Author(s), under exclusive licence to Springer Science+Business Media, LLC, part of Springer Nature 2021

\begin{abstract}
Purpose of Review Residency training is a pivotal educational step on the road to becoming a urologist. It combines both clinical and surgical instruction with the goal of producing proficient and compassionate surgeons and clinicians. In this review, we employ a SWOT analysis (Strengths, Weaknesses, Opportunities, and Threats) to investigate the current state of urologic residency training.

Recent Findings Urology remains an attractive and competitive residency with varied and complex surgical and medical training. Areas for improvement include standardization of evaluation and feedback, improving resident wellness, and expanding the use of surgical simulation. Workforce issues such as the predicted urologist supply deficit and poor readiness to enter the business of medicine can be addressed at the residency level. Failure to attract and retain underrepresented minorities, increasing burden of student debt, and resident burnout are serious threats to our field.

Summary Using a SWOT analysis we identify key areas for expansion, underscore valuable strengths, and provide a working roadmap for improvement of these formative years.
\end{abstract}

Keywords Urology $\cdot$ Residency $\cdot$ SWOT $\cdot$ Review

\section{Introduction}

After completing residency training, it is expected that the graduating urologist is both a competent surgeon and a capable clinician with the necessary knowledge and judgment to apply these surgical skills. This is a difficult balance to strike in the setting of a rapidly changing health care system, ongoing technological innovation, and residency work hour restrictions. It requires a systematic approach to resident education to ensure that trainees are prepared to provide excellent urologic care to the population.

Fortunately, within the field of urology, there is a strong foundation for resident education. This starts with the governing bodies, led by the American Urological Association (AUA), which support a culture of trainee growth and development. Additionally, there is a robust surgical training, which along with the growing use of surgical simulators, ensures that trainees are equipped to surgically treat a wide spectrum of disease processes. However, there remains room for improvement in how we educate trainees.

This article is part of the Topical Collection on Education

Lara S. MacLachlan

lara.maclachlan@lahey.org

1 Division of Urology, Lahey Hospital and Medical Center, Urology, Burlington, MA, USA
Residents are facing increasing levels of burnout and concerns over debt and lack of preparedness for entering the workforce. In addition, educational and surgical curricula remain variable across programs, particularly in the utilization of milestones, evaluations, and feedback. The need to improve urology residency training is necessary now more than ever, with the limited supply of urologists projected to fall short of demand from the aging population [1•]. We must reassess and adapt our approach in order to create a sustainable future for the next generation of urologists.

A SWOT analysis is a strategic planning technique used to evaluate an organization's strategic position. The analysis is broken down into four core elements - strengths, weaknesses, opportunities for improvement, and threats. In this article, a SWOT analysis is used to examine the state of urology residency training in America. While this analysis is essential, it should be utilized as part of a larger strategy along with interventions and outcome measures to improve the current system.

\section{Strengths}

Urology is a competitive field and there continues to be high demand for urology residency spots. In 2021, 481 medical students submitted rank lists for 357 residency positions, yielding a $74 \%$ match rate [2]. For US and 
Canadian senior medical students, the match rate was $80 \%$. This rate is similar to that of US MD seniors who matched to neurological surgery $(80 \%)$, plastic surgery $(80 \%)$, and orthopedic surgery (78\%) [3]. Within the main residency match, only otorhinolaryngology had a lower match rate at $72 \%$ [3]. The number of submitted rank lists has remained over 400 in all but 1 year since 2014, indicating that the demand to enter the field of urology is stable [2]. Urology clearly remains a desired career path for medical students, supporting a strong future for residency training.

Another strength is the breadth and depth of the surgical experience. This variety is captured by minimum index case requirements established by The Accreditation Council for Graduate Medical Education (ACGME). These thresholds are designed to ensure that the resident becomes a competent and safe surgeon in all fields of urology. In a study of case logs of urology residents graduating from 2010 to 2018, mean case volumes for trainees exceeded minimum case requirements in all categories and subspecialties by several fold, ranging from 170 to $550 \%$ [4]. From this perspective, urology residents currently receive a robust surgical experience. However, case volumes are not a perfect barometer of surgical proficiency. While there is literature to support the relationship between surgical volume and surgical proficiency, these minimum case requirements are produced by expert opinion with a paucity of direct supporting data [5]. No validated instruments are currently used at a national level to verify a resident's progression with regard to surgical skills. Hence, the responsibility ultimately falls to the individual training program to determine each resident's surgical competency [4].

There is a formalized educational system developed by the AUA to ensure that residents have the tools to become competent clinicians. The AUA's online portal provides comprehensive resources such as the core curriculum and the surgical video library. These inform trainees on over 50 key topics in urology and allow for self-paced learning on both clinical and surgical subjects. Additionally, the AUA's clinical practice guidelines, policy statements, and best practice statements provide concise summaries of management of common urologic diseases.

There are also standardized checkpoints in residency in the form of in-service exams. These objectively assess the clinical knowledge of urology residents, and thereby assist program directors and residents in evaluating their progression as well as the strengths and weaknesses of their education. Another significant step toward the creation of a standardized curriculum is the creation of a set of training milestones by the ACGME. Beginning in 2012, the ACGME collaborated with the American Board of Urology (ABU) to create a list of milestones tailored to Urology residents within the six established core competencies of the ACGME - patient care, medical knowledge, system-based practice, practice-based learning and improvement, interpersonal and communication skills, and professionalism [6]. Each milestone is arranged into five levels through which a trainee is expected to progress during residency [7]. Level 4 is the proposed threshold for competency as an independent urologist. Thus, this is the target for graduating residents. The milestone system provides a framework for the assessment of each resident in these core elements and informs a program's Clinical Competency Committee during periodic reviews.

At this time, these milestones are novel and based on expert opinion. As such, they represent training goals rather than requirements for the progression and graduation of urology residents. However, this is a crucial first step, as data from across the country can be used to determine the value and applicability of these milestones and levels of proficiency for various levels of post-graduate education.

\section{Weaknesses}

The ACGME milestones are an important step to standardizing urologic training; however, the specifics of how these might be achieved or assessed are left to each individual program. The approach to teaching, feedback, and assessment of skills are program specific and vary widely. While there have been attempts to develop standardized tools to assess resident competency, especially as it relates to performing complex operations and procedures, none of these instruments is yet widely adopted. For instance, a global rating scale was developed using a single question - "How confident are you that the trainee is competent to perform this procedure independently on an average patient?" This was assessed in a single urologic surgery program and results showed that attending and resident assessments varied widely, sometimes by up to $80 \%$ [8]. They also found considerable variability in how harshly each individual attending rated. These outline just a few pitfalls of such a rating system. Other issues include the time burden of filling out feedback forms after each procedure, the administrative burden both in terms of cost and time, and the lack of a standardized validated instrument.

An additional weakness of the milestone approach is that some of the milestones fall outside of what has traditionally been taught in urologic residency. To take an example, one ACGME milestone focuses on engagement in quality improvement (QI). In a survey of urology program directors, almost all strongly desired that residents learn QI methodology and understand how to apply it to conduct a QI project, with $89 \%$ and $86 \%$ of respondents, respectively, but only $44 \%$ of programs offered formal education in the subject and $81 \%$ expressed need for support from a professional society 
[9]. Although programs agree on the importance of these milestones, not all programs are equally equipped to achieve resident competency in them.

As noted in the "Strengths" section above, the breadth and depth of surgical experience for urology residents is significant. This, however, does not come without drawbacks. As the use of robot-assisted surgery increases, the number of major open surgical cases correspondingly declines. An analysis of resident case logs from 11 US urology programs found that from 2012 to 2017 the percentage of robotically performed oncologic cases rose from 27.5 to $54.2 \%$ [10]. This study noted that there were significant differences in surgical technique (open vs robotic) between institutions, particularly in pediatrics, as well as between graduates of the same program. This finding is mirrored in an analysis of resident case logs from 2009 to 2016 which found significant inter-resident variability in case numbers with a 3.8-fold difference between the 10th and 90th percentile across all categories [11]. As training trends shift, it is important to monitor and regulate resident experience to ensure that graduating residents are prepared to enter independent practice.

Another weakness of urologic training is in teaching preparedness to enter the workforce. The latest census from the AUA shows that greater than $50 \%$ of practicing urologists are in a private practice setting [12]. However, formal teaching of practice management or business training is rare [13]. This reality stands in opposition to an existing ACGME Milestone related to system-based practice that specifically focuses on the physician role in the broader health care system. This is not a problem unique to urology. A survey of plastic surgery residents revealed that greater than half had no formal curriculum in business education and only $10 \%$ felt that the training was adequate [14]. Various efforts have attempted to address this deficiency, but as of yet, no broader curriculum or approach has been widely adopted [15].

Burnout is a psychological response to chronic stress and emotionally intense work which is comprised three types of feelings: emotional exhaustion, depersonalization, and low personal accomplishment [16]. Burnout has been linked to lower quality patient care, increased costs and reduced productivity for health care systems, and an adverse impact on physician well-being including substance use, depression, and suicidal ideation [17]. Within the field of urology, physician burnout rates are on the rise, leading to an increasing interest in physician well-being throughout a career trajectory. Between 2011 and 2014, burnout among urologists increased from 41 to $63 \%$ [18]. Urology was ranked as the second-worst specialty in terms of both burnout and worklife balance. This trend is mirrored within graduate medical education (GME) as a survey of PGY2 residents revealed that urology residents had the highest proportion (63.8\%) of burnout symptoms out of all specialties examined [19••]. Increasing burnout was associated with a decreased quality of life and a reduced likelihood to choose urology again as a specialty in a survey of both American and European urology residents [20]. Some of the factors identified as protective against burnout included a mentorship program, time for non-medical reading, better work-life balance, access to mental health services, and not working $3+$ weekends a month. Poor quality of life and high levels of physician burnout can have wide ranging effects on the healthcare system but may also deter prospective applicants and hinder the education of current urologic residents.

The intersection of the COVID-19 pandemic and the Black Lives Matter movement has brought much needed attention to the structural racism that leads to racial disparities in health outcomes. Although the American College of Physicians first published a position paper in 2004 (with an update in 2010) that addressed these racial and ethnic disparities, there is a new urgency to address these inequities [21]. One of the key strategies to improve minority health outcomes is the recruitment and retainment of physicians from underrepresented minorities [22]. Unfortunately, the field of urology is lagging its peers in this mandate. A retrospective review of ACGME data shows that non-Asian minorities comprise just $17.7 \%$ of urology residents versus $25.6 \%$ in all medical specialties [23]. This trend is further perpetuated among practicing urologists. For example, black/African American people make up 12.4\% of the US population, but only account for $6.9 \%$ of graduating medical students, $3.7 \%$ of urology residents, and $2.1 \%$ of practicing urologists [24-27]. In order to provide exemplary care to under-represented minorities and socioeconomically disadvantaged patients, we need to focus our recruitment and retainment efforts on increasing diversity among providers within the field.

\section{Opportunities}

With the identification of burnout, mental illness, and suicidality as major contributors to resident dissatisfaction and medical errors, renewed focus has turned to resident well-being. This is an understudied but exciting opportunity to improve urology residency. Numerous small studies have investigated a variety of interventions from access to a gym, to a program to strengthen coping mechanisms, to triannual faculty consultation to discuss goals, progress, and well-being, all of which were aimed at improving resident wellness [28]. A recent publication highlighted the benefit of a comprehensive wellness curriculum aimed at changing program culture [29]. This study found that over the 3 years studied, a formalized curriculum improved metrics of resident burnout, with the most meaningful intervention being resident-organized social outings. While the efficacy of many of these interventions remains 
to be fully elucidated, this is an area many urologic programs have earmarked for expansion.

Along the same vein, resident work hours have been identified as one of the key potential contributors to physician burnout in addition to affecting many key indicators of physician wellness [30]. Nationally, the ACGME has placed hard stops on resident work hours following the high-profile death of Libby Zion at New York Hospital in 1984. A full account of these changes and the subsequent effect on residency training is beyond the scope of this review; however, long work hours is not an issue unique to residents. The burden is shared by attending urologists facing increased demand in the setting of the decreasing per capita urologic workforce [31]. Both issues can in part be alleviated by increased implementation of advanced practice providers (APPs) in Urology. The AUA issued a consensus statement endorsing the use of APPs in our field [32]. Specifically, these providers can be part of an integrated team and can first assist during robotic surgery, manage urology inpatients, and perform inpatient consults. While there are many established training paths to becoming an APP, only a few opportunities exist to specifically train these providers in matters specific to urology. For example, Mayo Clinic, Emory University, University of Texas Southwestern, University of Southern California, Lahey Hospital and Medical Center, Atrium Health, and University of Wisconsin all offer urology fellowships to APPs. Expansion of this pipeline will provide increased access to appropriately trained and invaluable members of the urologic team.

Some of the most exciting opportunities for urologic residency and the broader field lie in the interface between technology and surgery. Urology has been on the forefront of surgical innovation and there are many exciting recent technological trends which urologists have evaluated and adopted: from single-port robot-assisted laparoscopic surgery, to laser resection of bladder tumors, to single-use flexible ureteroscopes, to new approaches for benign prostatic hypertrophy. Examining new technology as a potential source of improvement in an area relevant to our field, whether it is improved patient outcomes, decreased costs, increased safety, or improved reproducibility, provides a rich learning environment in which residents are taught how to be adaptable in their surgical approach. This attitude creates opportunities for innovation, original research, industry partnerships, and most importantly improved patient care.

One area where technology directly interfaces with resident education is in the field of surgical simulation. Using simulation to familiarize the learner with certain aspects of a procedure or intricacies of a surgical tool provides a safe learning environment in which mistakes or errors can be made without harm to patients. Additionally, simulation can be used to provide repetition, improve efficiency, and build muscle memory. Three out of four urology residency program directors surveyed think that simulation improves operating room performance [33]. There exists a wide variety of simulators available to urology residents including robotic, laparoscopic, and endoscopic simulators. These vary widely in both their price and their face, content, and construct validity [34•]. What remains to be elucidated is the feedback mechanism through which residents using the simulators can judge their progress and target areas for improvement. While many instruments rely on expert observations, for example, the GEARS validated instrument to measure performance during a robotic procedure, the ideal surgical simulator would include this type of feedback without requiring an expert observer [35]. There have been several studies exploring video-assisted computer algorithms to determine performance metrics [36, 37]. While these are promising there is yet to be consensus and wide adoption of these feedback mechanisms. There is a great opportunity within the field of urology to continue improving on surgical simulators as well as the feedback mechanism through which residents can guide their improvement.

\section{Threats}

There are a number of key factors which threaten the success of graduate medical education including increasing concerns about the ability of current training pipelines to meet the needs of an aging population, escalating student loan debt, and the COVID-19 pandemic. These threats are not unique to urology residency programs; however, they must be addressed.

The demand for urologic care is predicted to increase dramatically due to an aging population with increased prevalence of urologic conditions [31]. This is complicated by an aging urologic workforce, with a median urologist age of 55 and greater than $30 \%$ of urologists aged 65 or older [12]. There is predicted to be a urologist supply deficit of $43 \%$ in 2035 if demand remains at current levels [1•]. While expansion of APPs will help bridge this gap, the number of urologists trained will need to be substantially increased. Since 2014 the number of urologic residency positions has increased from 285 to 357 , a $25 \%$ increase; however, this is not enough to mitigate the effect of retirement $[1 \bullet, 2]$. The generation of new federally funded residency positions has proven to be a politically complex issue, but the recent expansion of urology positions while GME funding has been frozen demonstrates that this is an achievable task even without federal support [38]. Our field will need to develop innovative ways to continue to meet the demand of the aging population.

Further threatening urology training is the current student debt crisis. According to the AAMC, the median cost to 
attend 4 years of medical school has risen from $\$ 227,000$ in 2009 to $\$ 272,000$ in 2019 [39]. Tuition has risen at a rate approximately twice as high as inflation in this 10-year period. The median level of debt for those who take out loans has also outpaced inflation by $35 \%$ and rests at $\$ 200,000$ for the class of 2019. Unfortunately, this disproportionately affects black graduating medical students who have the highest rate of educational debt (91\%) as well as highest median indebtedness $(\$ 230,000)$. Individual degree of indebtedness has a dose response relationship with stress levels and may have negative effects on academic performance [40•]. The effect of student debt on specialty choice is more controversial, with some studies suggesting that high levels of debt are associated with choosing a higher paying specialty, while other studies show no effect or the inverse [40•]. Increasing debt burden has also been shown to affect non-work-related life decisions such as delaying marriage, delaying home buying, and delays in family planning [41]. It is possible that rising debt could affect interest in research, applications for fellowship, or preference for private versus academic practice, though these have not yet been studied. Thus, rising indebtedness has a multitude of downstream effects and poses a major threat to urology residency training.

The COVID-19 pandemic caused major disruptions to resident training and recruitment. In many areas of the country elective surgeries were halted, residents were redeployed to medical floors and ICUs, clinics emptied in favor of telemedicine visits, and academic activities were cancelled or conducted online [42•]. The wide range of effects these changes have had on urology residents' training and wellness is largely unknown. A survey of urology residency program directors in April of 2020 revealed that designated clinical days dropped from 4.7 to 2.1 days per week, and $26 \%$ of programs had redeployed residents into other fields [43]. Sixty percent of program directors were concerned that residents would not meet minimum case requirements. A cross-sectional study capturing responses from 20\% of urology residents in April of 2020 found that factors such as cancellation of elective cases and PGY-4 or -5 status were risk factors for increased concern about the ability to operate independently as an attending [42•]. Reimbursement for telehealth visits has also altered the outpatient care delivery and resident training environment [44]. It remains to be seen how durable these changes are and any downstream impacts they have on resident education. In order to comply with social distancing and travel restrictions, the pandemic also necessitated a change in the recruitment and matching process for incoming residents. Nearly all in-person sub-internships were cancelled and replaced by a swath of virtual sub-internships, resident meet-and-greets, public lectures, and town halls. Residency interviews were also conducted virtually, resulting in an increased number of applicants matching at their home programs within plastic surgery and otolaryngology. However, neurosurgery and urology applications did not have a higher home program match rate [45]. This finding was confirmed by another study which looked more specifically at geographic dispersal patterns of matched urology applicants, with no difference in geographic distribution demonstrated following the COVID-19 pandemic [46]. The impact of decreased exposure to programs from the applicant point of view on satisfaction with rank lists has yet to be elucidated. Overall, it is clear that the COVID-19 pandemic is a major threat to urology residency training.

\section{Conclusions}

Urology residency is a competitive field with high demand. Residents receive a wide breadth and depth of clinical experience. Education is bolstered by strong national curricula and the adoption of formal milestones as measures of trainee progress. The weakness discussed here includes difficulty in objectively measuring progress along these broad milestones. Compounding this difficulty are milestones that fall outside the expertise or knowledge of existing faculty and teaching materials. There is additionally inadequate teaching of the essential business skills necessary for practice management. Resident burnout and a lack of diversity are also key areas for improvement.

There is a wealth of opportunities for the improvement of urologic training. Development of programs that focus on resident wellness will improve the resident experience during their training and in turn, further attract highly qualified students to the field. Greater incorporation of APPs into urologic practice will help offload the strain of increasing demands on urologic services. Continued engagement in technological advancements and surgical simulation will keep urologists at the center of innovation within the surgical subspecialties.

The threats identified here are major hurdles that must be addressed for urology to continue to be a desirable and satisfying career path. A pending physician shortage, rising educational debt, and the repercussions of the COVID-19 pandemic all detract from the overall mission of training. Innovative and paradigm-shifting solutions are needed to continue to move the field in a positive direction.

Author Contribution Lara MacLachlan conceptualized the article. Lara MacLachlan, Luke Sebel, and Eric Katz performed the literature review. Luke Sebel and Eric Katz drafted the article. Lara MacLachlan, Luke Sebel, and Eric Katz critically revised the article.

Availability of Data and Material Not applicable.

Code Availability Not applicable. 


\section{Declarations}

Ethics Approval Not applicable.

Consent to Participate Not applicable.

Consent for Publication Not applicable.

Conflict of Interest Drs. Sebel, Katz, and MacLachlan have nothing to disclose.

Human and Animal Rights and Informed Consent This article does not contain any studies with human or animal subjects performed by any of the authors.

\section{References}

Papers of particular interest, published recently, have been highlighted as:

- Of importance

$\bullet$ Of major importance

1.- McKibben MJ, Kirby EW, Langston J, Raynor MC, Nielsen ME, Smith AB, et al. Projecting the urology workforce over the next 20 years. Urology [Internet]. Elsevier Inc. 2016;98:21-6. With rising demand for urologic care, there may be a significant shortfall of urologic providers in the next 20 years.

2. Urology and Specialty Matches [Internet]. Available from: https://www.auanet.org/education/auauniversity/for-residents/ urology-and-specialty-matches

3. Main Residency Match Data and Reports [Internet]. Available from: https://www.nrmp.org/main-residency-match-data/

4. Silvestre J, Caruso VA, Hernandez JM, Lee DI. Longitudinal assessment of adult cases performed by graduating urology residents in the United States: 2010-2018. Urology Practice. 2020;7:53-60.

5. Halm EA, Lee $\mathrm{C}$, Chassin MR. Is volume related to outcome in health care? A systematic review and methodologic critique of the literature. Ann Intern Med. 2002;137:511-20.

6. Hamawy KJ, Edgar L. Urology milestones 2.0: the future looks bright. Curr Urol Rep. 2019;20:1-5.

7. Griffith JJ, Sagalovich D, Weissbart SJ, Stock JA. The current state of urological residency education. Urology Practice. 2016;3:224-9.

8. Schatz A, Kogan B, Feustel P. Assessing resident surgical competency in urology using a global rating scale. J Surg Educ. [Internet]. Elsevier. 2014;71:790-7.

9. Ziemba JB, Matlaga BR, Tessier CD. Educational resources for resident training in quality improvement: a national survey of urology residency program directors. Urology Practice [Internet]. Elsevier Ltd. 2018;5:398-404.

10. Merrill SB, Sohl BS, Thompson RH, Reese AC, Parekh DJ, Lynch JH, et al. The balance between open and robotic training among graduating urology residents-does surgical technique need monitoring? J Urol. 2020;203:996-1002.

11. Wingate J, Joyner B, Sweet RM, Hagedorn JC, Johnsen NV. Inter-resident variability in urologic operative case volumes over time: a review of the ACGME case logs from 2009 to 2016. Urology [Internet]. Elsevier Inc. 2020;142:49-54.

12. American Urological Association. 2020 The state of the urology workforce and practice in the United States.
13. Beiko D, Gonzalez CM, Mourtzinos AP, Rhee EY. Exploring the business of urology: Is it time for a "business of healthcare" curriculum in urology residency programs? Can Urol Assoc J. 2018;12:299-300.

14. Ovadia SA, Gishen K, Desai U, Garcia AM, Thaller SR. Education on the business of plastic surgery during training: a survey of plastic surgery residents. Aesthetic Plastic Surgery [Internet]. Springer US. 2018;42:886-90.

15. Patel R, Rhee K, Barone J, Elsamra SE. Business education for residents: results of a pilot business course at a urology residency program. Urology Practice [Internet]. Elsevier Ltd. 2018;5:107-12.

16. Maslach C. Jackson SE. Leiter MP. Maslach Burnout Inventory Manual [Internet]. 4th Editio. Mind Garden Inc. 2018. Available from: http://www.amazon.com/Maslach-Burnout-InventoryManual-Christina/dp/9996345777

17. West CP, Dyrbye LN, Shanafelt TD. Physician burnout: contributors, consequences and solutions. J Intern Med. 2018;283:516-29.

18. Shanafelt TD, Hasan O, Dyrbye LN, Sinsky C, Satele D, Sloan $\mathrm{J}$, et al. Changes in burnout and satisfaction with work-life balance in physicians and the general US working population between 2011 and 2014. Mayo Clin Proc. [Internet]. Elsevier Inc. 2015;90:1600-13.

19.• Dyrbye LN, Burke SE, Hardeman RR, Herrin J, Wittlin NM, Yeazel M, et al. Association of clinical specialty with symptoms of burnout and career choice regret among US resident physicians. JAMA - Journal of the American Medical Association. 2018;320:1114-30. Second year urology residents were found to have the highest rate of burnout of all specialties examined.

20. Marchalik DC, Goldman CFL, Carvalho F, Talso MH, Lynch J, Esperto F, et al. Resident burnout in USA and European urology residents: an international concern. BJU International. 2019;124:349-56.

21. American College of Physicians. Racial and ethnic disparities in health care: a position paper of the American College of Physicians. Ann Intern Med. 2004;141:226-32.

22. Betancourt JR, Green AR, Carrillo JE, Ananeh-Firempong O. Defining cultural competence: a practical framework for addressing racial/ethnic disparities in health and health care. Public Health Rep. 2003;118:293-302.

23. Shantharam G, Tran TY, McGee H, Thavaseelan S. Examining trends in underrepresented minorities in urology residency. Urology [Internet]. Elsevier Inc. 2019;127:36-41.

24. American community survey 1-year estimates. [Internet]. 2019. Available from: https://data.census.gov/cedsci/profile?q= UnitedStates\&g=0100000US

25. Dai JC, Agochukwu-Mmonu N, Hittelman AB. Strategies for attracting women and underrepresented minorities in urology. Curr Urol Rep. 2019;20.

26. AAMC. AAMC Medical School Graduation Questionnaire [Internet]. 2020. Available from: https://www.aamc.org/media/ 46851/download

27. ACGME. Data Resource Book Academic Year 2019-2020 [Internet]. 2020. Available from: https://www.acgme.org/ globalassets/PFAssets/PublicationsBooks/2019-2020_ACGME_ DATABOOK_DOCUMENT.pdf

28. Raj KS. Well-being in residency: a systematic review. J Grad Med Educ. 2016;8:674-84.

29. Anaissie J, Popat S, Mayer WA, Taylor JM. Innovative approaches to battling resident burnout in a urology residency program. Urology Practice. 2021;8:387-92.

30. Pulcrano M, Evans SRT, Sosin M. Quality of life and burnout rates across surgical specialties: a systematic review. JAMA Surg. 2016;151:970-8. 
31. Pruthi RS, Neuwahl S, Nielsen ME, Fraher E. Recent trends in the urology workforce in the United States. Urology [Internet]. Elsevier Inc. 2013;82:987-94.

32. Gonzalez CM, Brand T, Koncz L, Mitchell K, Spitz A, Quallich $\mathrm{S}$, et al. AUA consensus statement on advanced practice providers: executive summary. Urology Practice. 2015;2:219-22.

33. Kamel M, Eltahawy EA, Warford R, Thrush CR, Noureldin YA. Simulation-based training in urology residency programmes in the USA: results of a nationwide survey. Arab Journal of Urology [Internet]. Arab Association of Urology. 2018;16:446-52.

34. Childs BS, Manganiello MD, Korets R. Novel education and simulation tools in urologic training. Curr Urol Rep. 2019;20. Comprehensive review of the use of simulation tools in urologic training.

35. Goh AC, Goldfarb DW, Sander JC, Miles BJ, Dunkin BJ. Global evaluative assessment of robotic skills: validation of a clinical assessment tool to measure robotic surgical skills. Journal of Urology [Internet]. Elsevier Inc. 2012;187:247-52.

36. Hung AJ, Chen J, Jarc A, Hatcher D, Djaladat H, Gill IS. Development and validation of objective performance metrics for robot-assisted radical prostatectomy: a pilot study. Journal of Urology [Internet]. Elsevier. 2018;199:296-304.

37. Handelman A, Schnaider S, Schwartz-Ossad A, Barkan R, Tepper R. Computerized model for objectively evaluating cutting performance using a laparoscopic box trainer simulator. Surgical Endoscopy [Internet]. Springer US. 2019;33:2941-50.

38. Grischkan JA, Friedman AB, Chandra A. Moving the financing of graduate medical education into the 21st century. JAMA Journal of the American Medical Association. 2020;324:1035-6.

39. AAMC. Physician education debt and the cost to attend medical school [Internet] Available from: https://store.aamc.org/ downloadable/download/sample/sample_id/368/

40.• Pisaniello MS, Asahina AT, Bacchi S, Wagner M, Perry SW, Wong ML, et al. Effect of medical student debt on mental health, academic performance and specialty choice: A systematic review. BMJ Open. 2019;9:1-15. A systematic review on the effect of medical student debt on well-being, performance, and specialty choice.

41. Rohlfing J, Navarro R, Maniya OZ, Hughes BD, Rogalsky DK. Medical student debt and major life choices other than specialty. Medical Education Online. 2014;19.

42.• Khusid JA, Weinstein CS, Becerra AZ, Kashani M, Robins DJ, Fink LE, et al. Well-being and education of urology residents during the COVID-19 pandemic: results of an American National Survey. Int J Clin Pract. 2020;74:1-8. One of the earliest studies looking at urology resident well-being and education during the COVID-19 pandemic.

43. Rosen GH, Murray KS, Greene KL, Pruthi RS, Richstone L, Mirza M. Effect of COVID-19 on urology residency training: a nationwide survey of program directors by the Society of Academic Urologists. J Urol. 2020;204:1039-45.

44. Patel SY, Mehrotra A, Huskamp HA, Uscher-Pines L, Ganguli I, Barnett ML. Trends in outpatient care delivery and telemedicine during the COVID-19 pandemic in the US. JAMA Internal Medicine. 2021 Mar 1;181(3):388-91.

45. Faletsky A, Zitkovsky H, Guo L. Disparate responses in match outcome across competitive surgical subspecialties to pandemic era constraints: an analysis of impacts of minimal auditions. $\mathbf{J}$ Surg Educ. [Internet]. Elsevier Inc. 2021;1-6.

46. Gabrielson AT, Meilchen CK, Kohn JR, Kohn TP. The COVID19 residency application cycle did not affect geographic dispersal patterns among applicants entering the urology match: a quantitative mapping study. Urology [Internet]. Elsevier Inc. 2021;1-7.

Publisher's Note Springer Nature remains neutral with regard to jurisdictional claims in published maps and institutional affiliations. 